\title{
EMOTIONAL INTELLIGENCE OF BOYS AND GIRLS STUDYING IN UNDERGRADUATE COURSES
}

\author{
Maniya Anil A.* \\ Chauhan Ajay J.*
}

\begin{abstract}
The present study about of emotional Intelligence Level of Arts and Commerce Students. Total 40 students were selected randomly Anand district area's colleges. In which 20 students (10 males and 10 females) from Arts faculties and also 20 students (10 male and 10 females) from commerce faculty.

After analysis was done according to key for the comparison of difference group ' $t$ ' test was calculated.

\section{Introduction}

Emotions process an important position in human life, Emotion is a daily experience encored in daily human life. Internal changes occurred in body of a person during situation of emotion. External expression of emotional is also occurred along with it. Emotions are connected as a part of our daily life. Emotional factor is stayed (remained) in our every activity and experience. Emotions are also happened as internal situation and inspired to of our behavior. Life without emotion becomes without interest, dry, without sentiments and just like a cold marrow us situation. Emotions make our life interested, live and enthusiastic. On the other side, it can bring destroying, friction and bitterness also in our life.
\end{abstract}

\section{Definitions of Emotion}

1. 'Emotion means dismayed position of total nervous system.'

- Wood worth and mark Wish

*\&**M.A, Department of psychology, S.P. University, Vallabh Vidyanagar

(c) www.ijip.in 
2. 'Emotion means excessive activity of nervous system.'

- Linds

3. 'Emotion is an acute experience disturbing total nervous system which is experienced by everyone.'

- Crow \& Crow

4. 'Physical dismayance or disturbing situation occurring in body.'

- An applicable definition

\section{Meaning of Emotions}

The word 'emotion' is come down from the letin word 'Emovere'. Its meaning is dismaying or disturbing. Some psychologists identified emotion as sentimental situation of feeling to light mental situation like happy and sorrow.

In view of physical metabolism the central factor of emotion is a strife (dualism) of sleep and anxiety. In anxiety physical metabolism is at peak. In sleeping position sentiment and activity both are at lowest level. In this way sleep and anxiety are two extreme borders of emotional life.

\section{Nature of Emotion:-}

Following four matters (things) are main to make clear form of emotion.

1. Mental experience of emotion.

2. External expression at the time of emotion.

3. Internal changes occured during emotion.

4. Inspiration gained by emotion.

\section{Physical changes during emotion}

Internal physical changes which occur during emotion can be divided into following six kinds:-

1. Change in rate of blood circulation

2. Change in rate of digestion

3. Change in rate of respiration.

4. Change in rate of intra-gland liquids.

5. Galvenicskin response.

6. Other changes.

\section{Contribution of automated nervous system during emotional process.}

There are two different systems in automated nervous systems but both are supplementary to each other.

(C) www.ijip.in 
1. Compassions nervous system.

2. Un-capacious (depending) nervous system.

\section{Objectives:}

1. To know the difference between the emotional intelligence level of male and female students.

2. To know about the emotional intelligence level of Arts and Commerce students.

3. To know the difference between the emotional intelligence level of male and female from Arts group.

4. To know the difference between the emotional intelligence level of male and female from Commerce group.

\section{Hypothesis:}

1. There is no difference of emotional intelligence level of Arts male and female.

2. There is no difference of emotional intelligence level of Commerce male and female.

3. There is no difference of emotional intelligence level of Arts and Commerce male students.

4. There is no difference of emotional intelligence level of Arts and Commerce female students.

5. There is no difference of emotional intelligence level of male and female students.

\section{Variable:}

In present research following variables are shown in this table

\begin{tabular}{lll}
\hline Name of Variable & Nature of Variable & Number of Variable \\
\hline Two* Groups & IV & 03 \\
Emotional Intelligence & DV & 04 \\
Gender & IV & 02 \\
\hline
\end{tabular}

IV $=$ Independent Variable, DV = Dependent Variable, $*$ Arts and Commerce

\section{Sampling:}

\begin{tabular}{llll}
\hline Group & Male & Female & Total \\
\hline Arts & 10 & 10 & $\mathbf{2 0}$ \\
Commerce & 10 & 10 & $\mathbf{2 0}$ \\
- & - & - & - \\
Total & $\mathbf{2 0}$ & $\mathbf{2 0}$ & $\mathbf{4 0}$ \\
\hline
\end{tabular}




\section{Tools:}

In the presents studies for finding of emotional intelligence level on the Arts and commerce students the main objectives of this research. Percentage score presents study is for finding out the "EMOTIONAL INTELLIGENCE SCALE" (EIS) test used. Developed by Anukool Hyde, SanjyotPethe, Upinder Dhare (2001) (Translated in Gujarati by Rathod, 2009)

\section{Research Design:}

40 male and female students were selected randomly ANAND district area's local colleges. Students were divided in two groups. Group one 'Arts', in which 20 persons (10 male and 10 female). Number of two group 'commerce', in which 20 persons (10 males and 10 females).

After collecting the date statistical analysis was done according to key for the comparison of different groups ' $t$ ' test was calculated.

\section{Results and Discussion:}

Table no.1: Male and female from Arts group.

\begin{tabular}{|c|c|c|c|c|c|c|}
\hline Groups & $\mathrm{N}$ & Mean & SD & SEM & $\mathrm{t} 1$ & Level $f$ \\
\hline Male & 10 & 97.30 & 11.55 & 3.65 & 3.5993 & $\mathrm{NS}$ \\
\hline Female & 10 & 115.60 & 11.19 & 3.54 & & 0.01 \\
\hline
\end{tabular}

- This table indicates no significant difference between male and female from Arts group. Females are more effective in emotional intelligence level.

Table no.2: Male and female from Commerce group.

\begin{tabular}{|l|l|l|l|l|l|l|}
\hline Groups & $\mathrm{N}$ & Mean & SD & SEM & $\mathrm{t}$ & Level \\
\hline Male & 10 & 108 & 15.37 & 4.86 & 0.6971 & NS \\
\cline { 1 - 4 } Female & 10 & 113.60 & 20.23 & 6.40 & & 0.01 \\
\hline
\end{tabular}

- This table indicates no significant difference between male and female from Commerce group. Females are more effective in emotional intelligence level.

Table no.3: Male from Arts and Commerce group.

\begin{tabular}{|l|l|l|l|l|l|l|}
\hline Groups & $\mathrm{N}$ & Mean & SD & SEM & $\mathrm{t}$ & Level \\
\hline Male (A) & 10 & 97.30 & 11.55 & 3.65 & 1.7601 & NS \\
Male (C) & 10 & 108 & 15.37 & 4.86 & & 0.01 \\
\hline
\end{tabular}


- This table indicates no significant difference between males from Arts and Commerce group. Commerce males are more effective in emotional intelligence level.

Table no.4: Female from Arts and Commerce group.

\begin{tabular}{|l|l|l|l|l|l|l|}
\hline Groups & $\mathrm{N}$ & Mean & SD & SEM & $\mathrm{t}$ & Level \\
\hline Female (A) & 10 & 115.60 & 11.19 & 3.54 & 0.2736 & NS \\
\cline { 1 - 4 } Female(C) & 10 & 113.60 & 20.23 & 6.40 & & 0.01 \\
\hline
\end{tabular}

- This table indicates no significant difference between females from Arts and Commerce group. Arts females are more effective in emotional intelligence level.

Table no.5: All over male and female.

\begin{tabular}{|l|l|l|l|l|l|l|}
\hline Groups & N & Mean & SD & SEM & T & Level \\
\hline Male & 20 & 102.65 & 14.32 & 3.20 & 2.4936 & NS \\
Female & 20 & 114.60 & 15.94 & 3.56 & & 0.01 \\
\hline
\end{tabular}

- This table indicates no significant difference between male and female all group. Females are more effective in emotional intelligence level.

\section{Charts:}

1. Male and female from Arts group.

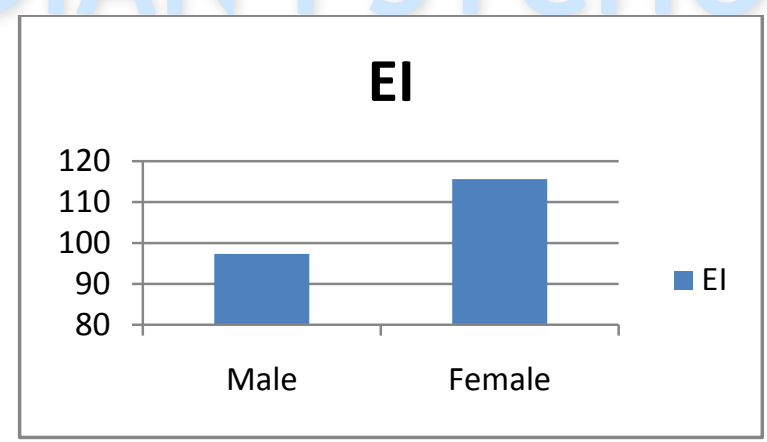

2. Male and female from Commerce group.

(c) www.ijip.in 
The International Journal of Indian Psychology: Volume: 02 | Issue: 02 | February 2014

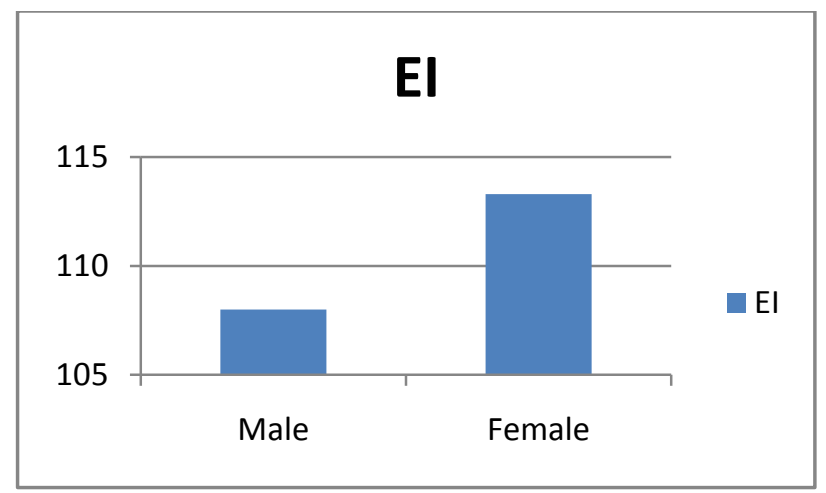

2. Male from Arts and Commerce group.

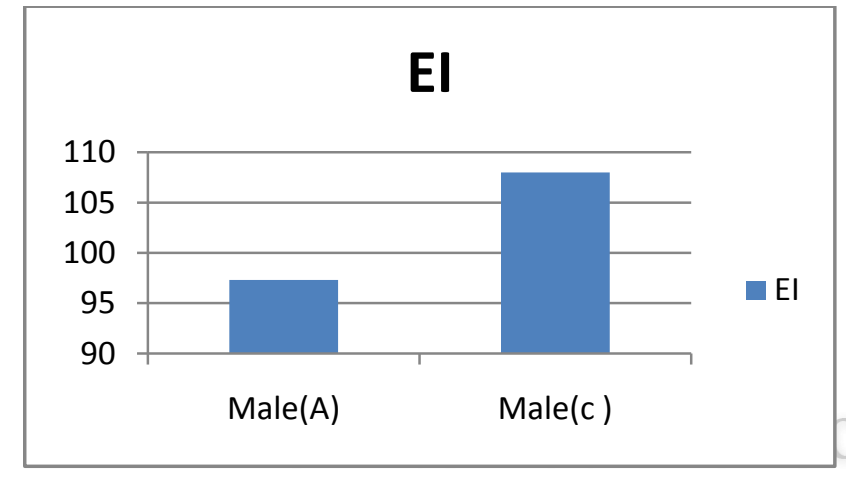

3. Female from Arts and Commerce group.

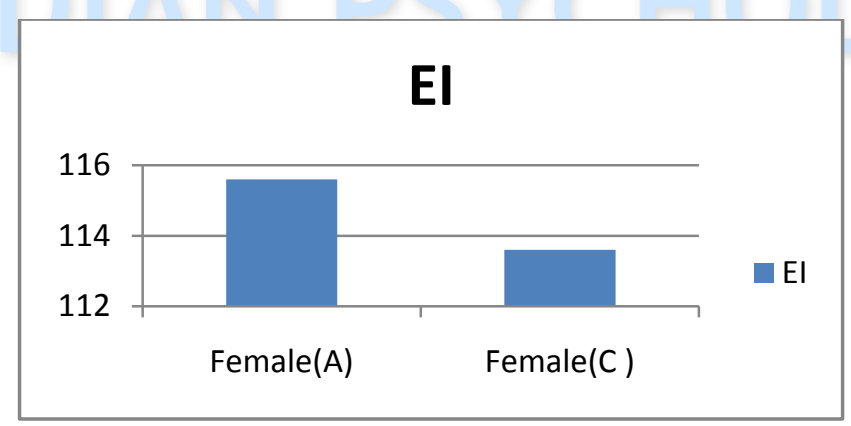

4. All over male and female.

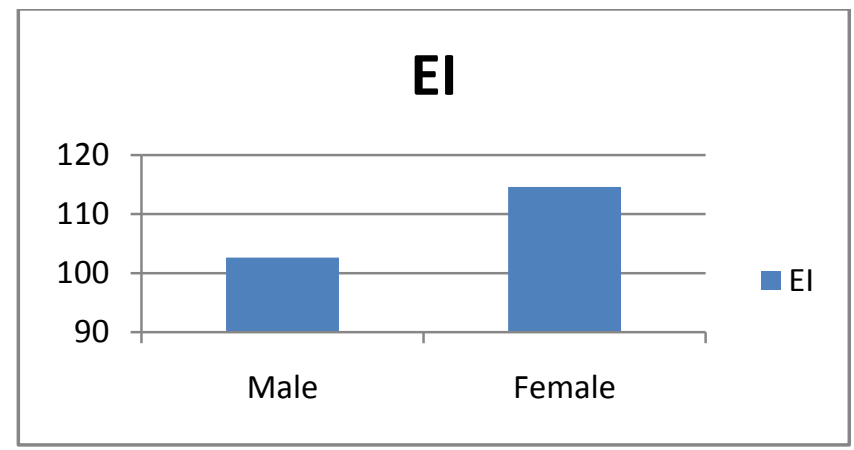

(c) www.ijip.in 


\section{Interpretation of Tables and Testing of Hypothesis:}

- HO1: There is no significant effect of emotional intelligence level between male and female of Arts group. Tested $t$ value is 3.5993 at 0.01 levels. So, we accepted of this null hypothesis.

- HO2: There is no significant effect of emotional intelligence level between male and female of Commerce group. Tested t value is 0.6971 at 0.01 levels. So, we accepted of this null hypothesis.

- HO3: There is no significant effect of emotional intelligence level between males of Arts and Commerce group. Tested $t$ value is 1.7601 at 0.01 levels. So, we accepted of this null hypothesis.

- HO4: There is no significant effect of emotional intelligence level between female of Arts and Commerce group. Tested $t$ value is 0.2736 at 0.01 levels. So, we accepted of this null hypothesis.

- HO5: There is no significant effect of emotional intelligence level between males and females. Tested t value is 2.4936 at 0.01 levels. So, we accepted of this null hypothesis.

\section{References:}

1. Adjustment Psychology, Dr. L.R. Yagnik, Dr. B.D. Dhila\& Dr. Arvind Shah, First Edi., 2005, Parshva Pub., Ahmadabad.

2. Advanced General Psychology, B.A. Parikh Third Ed., 2004, University GrantNirman Board, Gujarat State, Ahmedabad-380006.

3. Emotional Intelligence, Dr. M.S. Bhattacharya, and Dr. N. Sengupta, First Edution, 2007, New Delhi.

4. Physiological Psychology, Arvind Shah, Parshva Pub., Ahmadabad.

(c) www.ijip.in 